\title{
e-Navigating in highly-constrained waters: a case study of the Vistula Lagoon
}

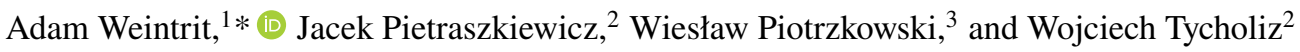 \\ ${ }^{1}$ Faculty of Navigation, Gdynia Maritime University, Gdynia, Poland. \\ ${ }_{3}^{2}$ NavSim Polska, Bolesławiec, Poland. \\ ${ }^{3}$ Maritime Office, Gdynia, Poland. \\ *Corresponding author. E-mail: a.weintrit@umg.edu.pl
}

Received: 18 November 2020; Accepted: 30 November 2020; First published online: 21 January 2021

Keywords: e-Navigation, GNSS-RTK GBAS, Vistula Lagoon, highly-constrained waters

\begin{abstract}
In recent years the transition of marine navigation to the digital era has been gaining momentum. Implementation of e-Navigation solutions varies from country to country in terms of their priorities, goals, levels and effects. Maritime authorities in Poland have been setting the pace in this transition process, not only in Poland but also in general as a global solution. The most recent example is the planned deployment of a variety of e-Navigation tools in the Vistula Lagoon: from GNSS-RTK Ground-Based Augmentation System, to virtual and synthetic aids to navigation, high-resolution bathymetry and advanced navigational software for piloting. The major objectives of this paper are, first, to summarise recent dynamics in the e-Navigation field, and second, to present a practical implementation of the e-Navigation concept in the Vistula Lagoon area.
\end{abstract}

\section{Introduction}

As technological progress advances in the maritime sector, so does the application range of e-Navigation tools and solutions. Literally, there is no week without pieces of news regarding a new e-Navigation application being implemented in the open sea, waterways, ports and vessels. For example, Inmarsat recently announced the introduction of ECDIS and ENCs update via L-band satellite link (Wingrove, 2019), ChartCo introduced an integrated e-Navigation and compliance platform integrating passage planning, documents handling and environmental system management (Digital Ship, 2018), whilst Hapag-Lloyd has installed Poseidon Navigation Services software on its container ships for updates of electronic and paper navigational charts (Maritime Logistics Professional, 2018).

In recent years Poland has become one of the leaders at the forefront of implementing e-Navigation solutions into practice (Weintrit et al., 2007). An analysis of operation of the maritime reference station in Świnoujście as the basis for creating the instrument docking system (IDS) (Pietraszkiewicz and Tycholiz, 2018), deployment of GBAS-RTK in the Outer Port of Świnoujście, a smart buoy manager system for monitoring and control of buoys and other maritime assets along the Świnoujście-Szczecin waterway, the SYMON assets control and monitoring system in Gdynia, and advanced PPU (portable pilot unit) systems for marine pilots in Szczecin and Gdańsk, are just a few examples of the latest practical advances in the implementation of the e-Navigation concept in Poland.

But seemingly the largest e-Navigation project in Poland is yet on the horizon, as the Polish government announces plans to revive the economy of north-eastern Poland by constructing a canal through the Vistula Spit (Mierzeja Wiślana) and a waterway connecting the Port of Elbląg with the Bay of Gdańsk - the Nowy Świat-Elbląg waterway. According to Poland's Ministry of Marine Economy and 
Inland Navigation, the completion of construction works and the commissioning of the shipping channel is planned for 2022. The new shipping channel will remove existing infrastructure barriers that limit the development of north-eastern Poland (Misnik, 2014).

The major objective of this paper is to present, using the Nowy Swiat-Elbląg waterway project as a case study, how e-Navigation has evolved as a complex concept and, more importantly, to what extent its application can contribute to safer and more efficient navigation in highly-constrained waters, in restricted (poor, very poor or even lack of) visibility and with a minimal use of physical aids to navigation.

This paper is divided into the following sections. The next section provides a theoretical framework and a critical overview of the literature concerning e-Navigation. Subsequently, we turn our attention to the particular case study of the Vistula Lagoon, presenting its unique environmental and navigational characteristics and constraints. The next section provides a detailed analysis of how e-Navigation tools and solutions can be applied to the Vistula Lagoon to improve efficiency and safety of navigation. The final section contains some important conclusions.

\section{Recent advances in e-Navigation}

The International Maritime Organisation (IMO) defines e-Navigation as 'the harmonized collection, integration, exchange, presentation and analysis of marine information on board and ashore by electronic means to enhance berth to berth navigation and related services for safety and security at sea and protection of the marine environment' (Weintrit et al., 2007; IMO, 2009; Weintrit, 2013; Hagen, 2017). It should be noted that the term e-Navigation is often used in a generic sense by equipment manufacturers and service providers. This claim should be seen as an aspiration, rather than an indication of compliance.

In more detail, e-Navigation is a concept to support and improve decision-making through maritime information management. It aims to (IMO, 2009; Weintrit, 2016a):

- improve the protection of the marine and coastal environment from pollution;

- enable higher efficiency and reduced costs in transport and logistics;

- facilitate the safe and secure navigation of vessels by improved traffic management, and through the promotion of better standards for safe navigation;

- improve contingency response, and search and rescue services;

- enhance management and usability of information onboard and ashore to support effective decision-making, and to optimise the level of administrative workload for the mariner.

e-Navigation aims to provide digital information for the benefit of maritime safety, security and protection of the environment, reducing administrative burdens and increasing the efficiency of maritime trade and transport (Hagen, 2017).

The work conducted by the IMO during the last few years has led to the identification of specific user needs and potential e-Navigation solutions. The e-Navigation Strategy Implementation Plan (SIP), which was approved in 2014, contains a list of tasks required to be conducted in order to address five prioritised e-Navigation solutions, namely (Weintrit, 2016b; IMO, 2018):

- improved, harmonised and user-friendly bridge design;

- means for standardised and automated reporting;

- improved reliability, resilience and integrity of bridge equipment and navigation information;

- integration and presentation of available information in graphical displays received via communication equipment; and

- improved communication of Vessel Traffic Service (VTS) portfolio (not limited to VTS stations).

The ultimate goal of e-Navigation is to integrate ship-borne and land-based technology on a so far unseen level. e-Navigation is meant to integrate existing and new electronic navigational tools (ship and shore based) into one comprehensive system that will contribute to enhanced navigational safety 
and security whilst reducing the workload of the mariner (navigator), (Patraiko et al., 2010; Hagen, 2017). The bridge between those two domains will be broadband communication technology which is about to arrive in regular commercial shipping within the next years to come. The constituting element of this integration, however, is a common maritime data model. The existing concept of the Geospatial Information Registry can be adapted to the enhanced scope of a future Marine Information Registry covering additional maritime domains by expansion, amendment and moderate rearrangement. Besides the recognised international organisations like the International Association of Marine Aids to Navigation and Lighthouse Authorities (IALA), International Hydrographic Organisation and IMO which are currently discussing the further steps in e-Navigation, a grass-roots movement may take place with several stakeholders involved in populating the Marine Information Registry. Such a grass-roots movement would truly demonstrate that e-Navigation has been understood and accepted. To allow for the orderly development of that stage of e-Navigation in accordance with the IMO defined goals and aspirations of e-Navigation, it would be necessary to activate the appropriate IMO instruments already in place to define the fundamental principles and structure of the Marine Information Registry, to assign roles and responsibilities amongst international organisations and stakeholders, and thereby facilitate the seventh pillar of e-Navigation, its 'cement', namely the Common Maritime Data Structure (CDMS) (Weintrit, 2011; Rødseth, 2016).

\section{Vistula Lagoon and the Nowy Świat-Elbląg waterway}

The waterway from Nowy Świat to Elbląg connects the city of Elbląg with the Bay of Gdańsk. The project includes a construction of a canal which will cut through a narrow strip of land (the Vistula Spit) separating the Vistula Lagoon (Zwolan and Czaplewski, 2015).

From the navigational perspective, passage along the Nowy Świat-Elbląg waterway can be divided into three legs: (1) Vistula Spit and locks; (2) Vistula Lagoon; (3) the Elbląg River (Figure 1).

Although e-Navigation solutions can be successfully utilised on each of the above mentioned legs, particular attention is devoted to the second leg, passage through the Vistula Lagoon, as it is the only leg where the deployment of physical aids to navigation is not planned. Therefore, e-Navigation services are going to constitute the fundamental means of navigational aids.

When preparing e-Navigation solutions for the area, the following aspects - as they all require attention when designing the e-Navigation layer of the waterway - require more detailed analysis: wind speed and direction, wave height and direction, water level, currents, visibility and icing. Although detailed analysis of these aspects is beyond the scope of this paper, we would like to present the most important hydrometeorogical determinants influencing e-Navigation concept in the region.

The Vistula Lagoon, similarly to the Baltic Sea, is mostly influenced by predominantly westerly atmospheric circulation. As a result, almost $50 \%$ of the wind direction in the region is from SW-NW sector. As for the wind speed, for most of the time it oscillates within the range of 2-4 Beaufort. The Vistula Lagoon, due to its location, is not characterised by high waves and strong currents. Nevertheless, as the average depth of water in the area is below $3 \mathrm{~m}$ (see Figure 2), the region is prone to short waves occurring during storms. The water level is relatively stable and the highest recorded amplitude was around $1.5 \mathrm{~m}$ (mostly due to wind activity). The average water level amplitude over the period 2016-2018 was $1.3 \mathrm{~m}$. Most of the time, however, the water level is either normal or high.

Although the eastern (Russian) part of the Vistula Lagoon is characterised by relatively strong currents due to its narrow connection with the Baltic Sea through the Strait of Baltiysk, the western (Polish) part of the lagoon is much more stable as the currents in the W-E axis average 0.02 knots (Tomaszewski et al., 2018). Assuming an average vessel speed in the N-S axis is around 5 knots, the vessel's drift is around $\pm 0 \cdot 3^{\circ}$. Having in mind the length $(10 \mathrm{~km})$ and width $(60 \mathrm{~m})$ of the waterway, the set and drift is not insignificant (48 $\mathrm{m}$ at $10 \mathrm{~km})$.

Visibility characteristics of the region are similar to the Bay of Gdańsk. Occasionally, mostly during autumn and spring time, there are days with a dense fog. Nevertheless, for most of the time the visibility in the region has no great influence on navigation. More important and troublesome from the navigational 


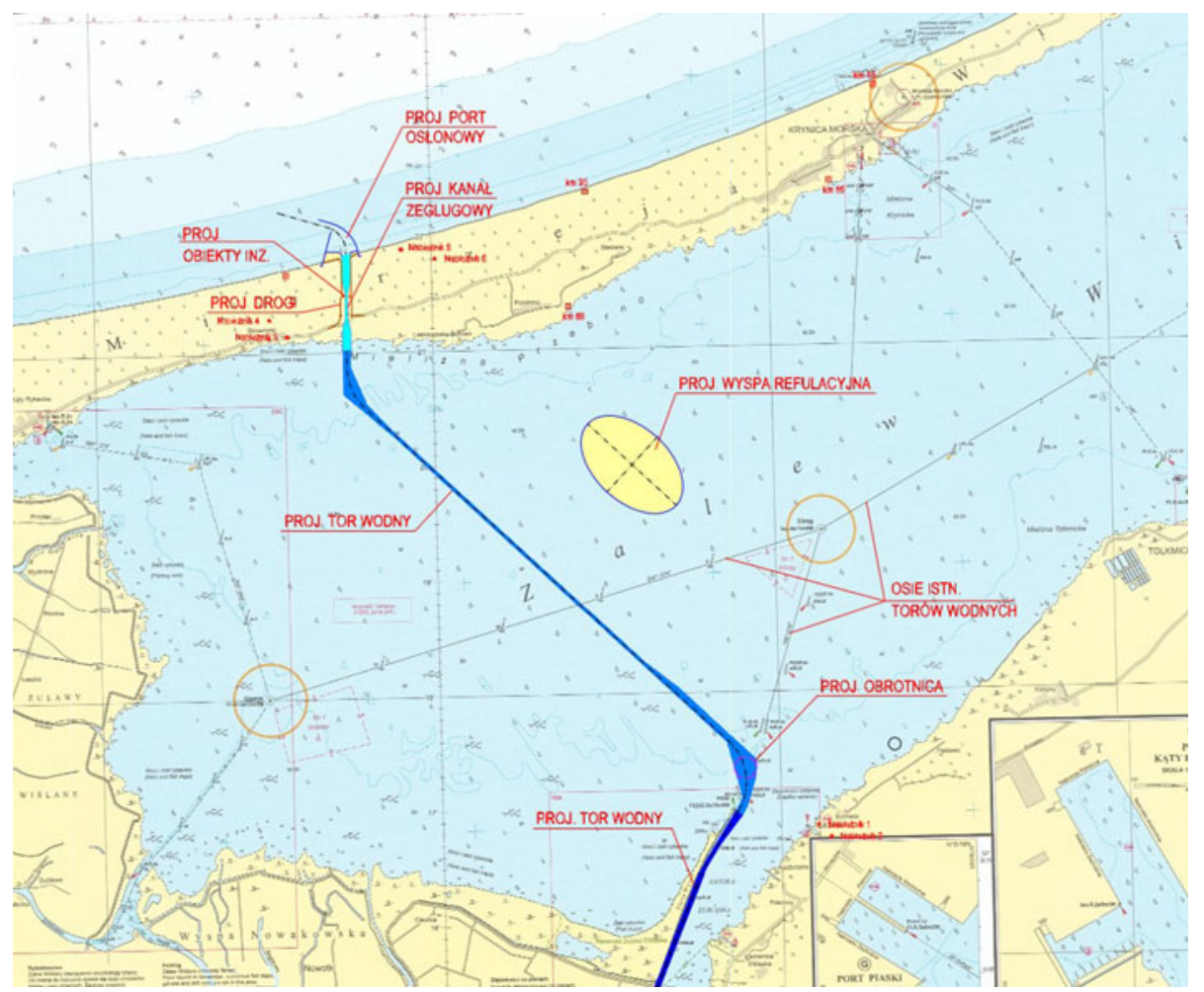

Figure 1. Overview of the Nowy Świat-Elbląg waterway. Source: Tomaszewski et al. (2018).

perspective is icing in winter time. Starting from early December the Vistula Lagoon covers with ice. Depending on the severity of the winter, the ice thickness ranges from 30 to $60 \mathrm{~cm}$. As the winter comes to an end in March, so does the icing cover of the lagoon.

\section{4. e-Navigation services planned for the Nowy Świat-Elbląg waterway - a practical approach}

\subsection{Automatic identification system aids to navigation}

The provision of information in a digital format adds to traditional navigation instruments and provides mariners with new tools in their decision-making processes. In situations where the deployment of physical aids to navigation is limited (or not possible at all) - as it is with our case study - broadcasting synthetic automatic identification system aids to navigation can in fact be the only feasible solution for providing critical information (IALA, 2011).

Automatic identification system (AIS) is the internationally adopted radio communication system that allows autonomous and continuous exchange of navigation safety messages between vessels, aircraft, shore stations and aids to navigation (AtoN). Broadcasts can originate from an AIS station located on an existing physical aid (real AIS AtoN) or from another location (AIS base station). When an AIS base station signal is broadcast to coincide with an existing physical aid it is known as a synthetic AIS AtoN (S-AtoN). When a signal is broadcast to a location on a waterway where there is no physical aid, it is known as a virtual AIS AtoN. All three variations can be received by any existing AIS mobile device, but they require an external system such as AIS message 21-capable ECDIS, ECS, radar or a personal computer.

Accordingly, mariners may need to base their decisions primarily on virtually displayed information visible on the ECDIS and PPU screen. To prepare mariners for the proper utilisation of the S-AtoN 


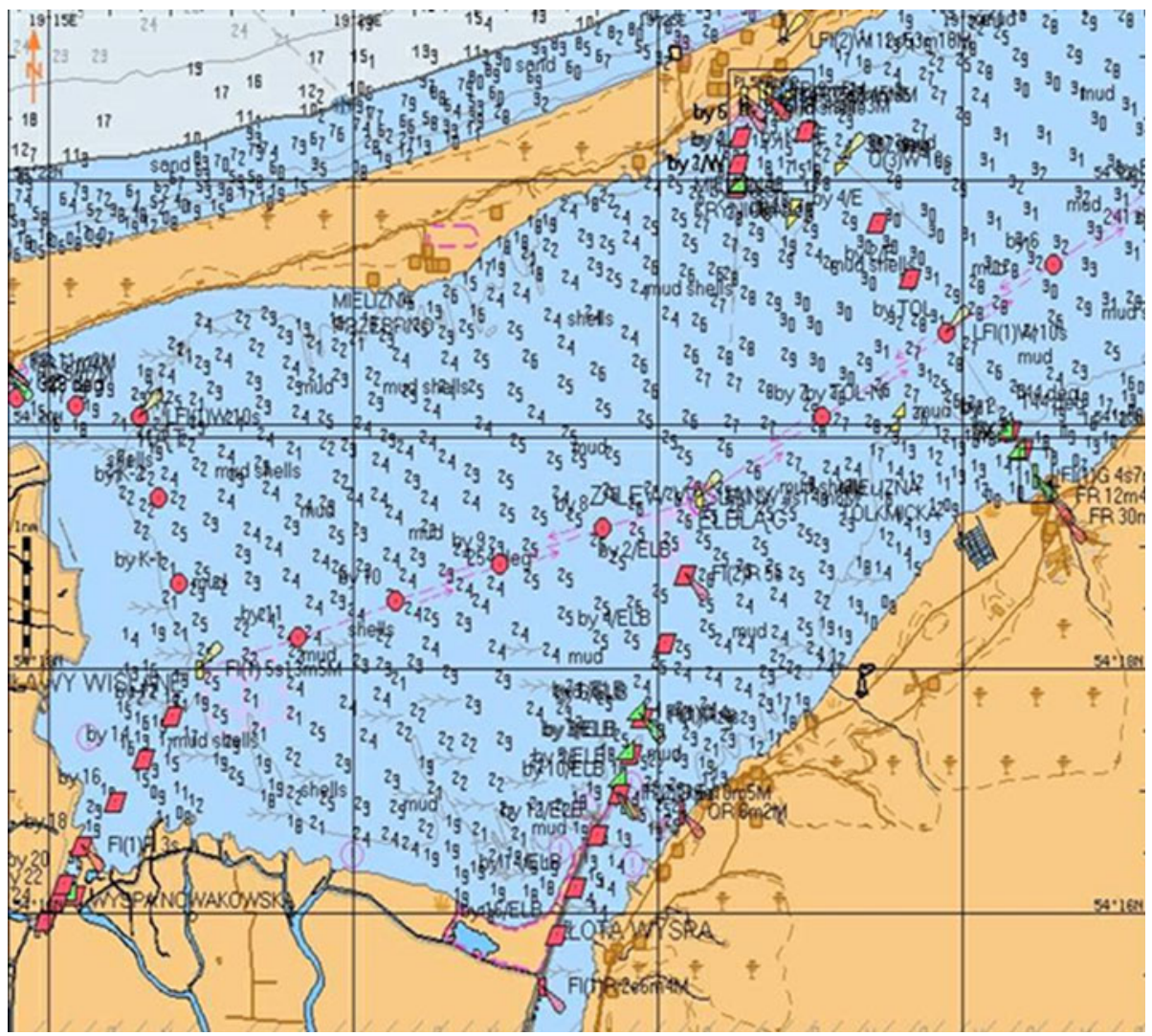

Figure 2. Depths in the western part of the Vistula Lagoon.

technology, the maritime authority in Gdynia has already deployed some virtual and synthetic AtoNs in the Bay of Gdansk area.

As the presence of physical AtoNs along the Nowy Świat-Elbląg waterway will be limited, following IALA Recommendation A-126 (IALA, 2011), S-AtoNs constitute a feasible alternative for marking borders of the waterway, buoys and other navigational objects. The S-AtoN can be further enhanced by AIS application-specific messages (AIS ASM), that is, an AIS-based system for delivering targeted information to pilots (e.g., about lock status, harbour information, fog detector status and others).

In most cases, for fixed AtoN the provision of AIS AtoN functionality on floating AtoNs, such as buoys and major floating aids (MFA), provides confirmation of the floating AtoN position. Confirmation of position provides the mariner with an assurance that the AtoN can be used, improves spatial awareness, enables measure of bearings and distances for position confirmation. As pointed out in the IALA Recommendation A-126 (IALA, 2011), 'advance confirmation of the position of floating AtoN is a significant improvement in the service available to the mariner'. Similarly, when deployment of floating AtoNs is limited (or impossible - as it is with the case Nowy Świat-Elbląg waterway), the same technology can be utilised to mark virtually the border of the waterway without MFAs (Figure 3).

The Nowy Świat-Elbląg waterway would not be the first location to utilise such an approach. In 2017 a similar e-Navigation service was introduced by the Danish Maritime Authority in the Odense Fjord area, where over 20 virtual AtoNs and S-AtoNs were deployed to mark the borders of a waterway.

The Virtual AtoN Generator (VAG) is a compact, rack-mounted device capable of deploying up 250 virtual and/or synthetic AIS AtoNs simultaneously. Thanks to a built-in scheduler, the operator can plan ahead for deployment of new or removal of existing AIS AtoNs and have full control over the time when and how they are visible to vessels. The transmission capability allows not only for generating 


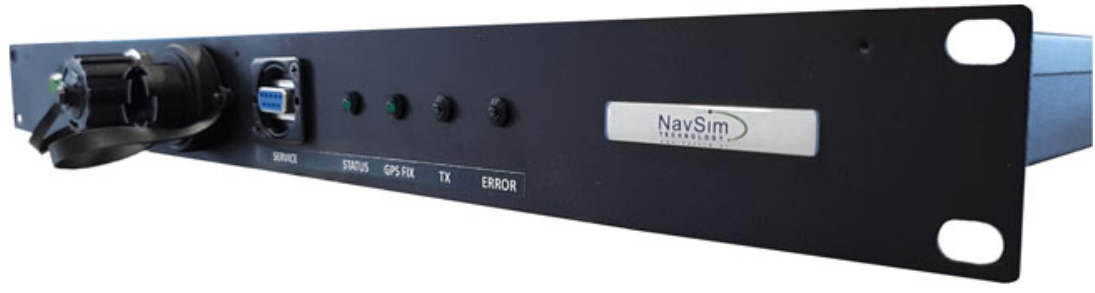

Figure 3. Virtual AtoN generator (front view, 19-inch rack mount).

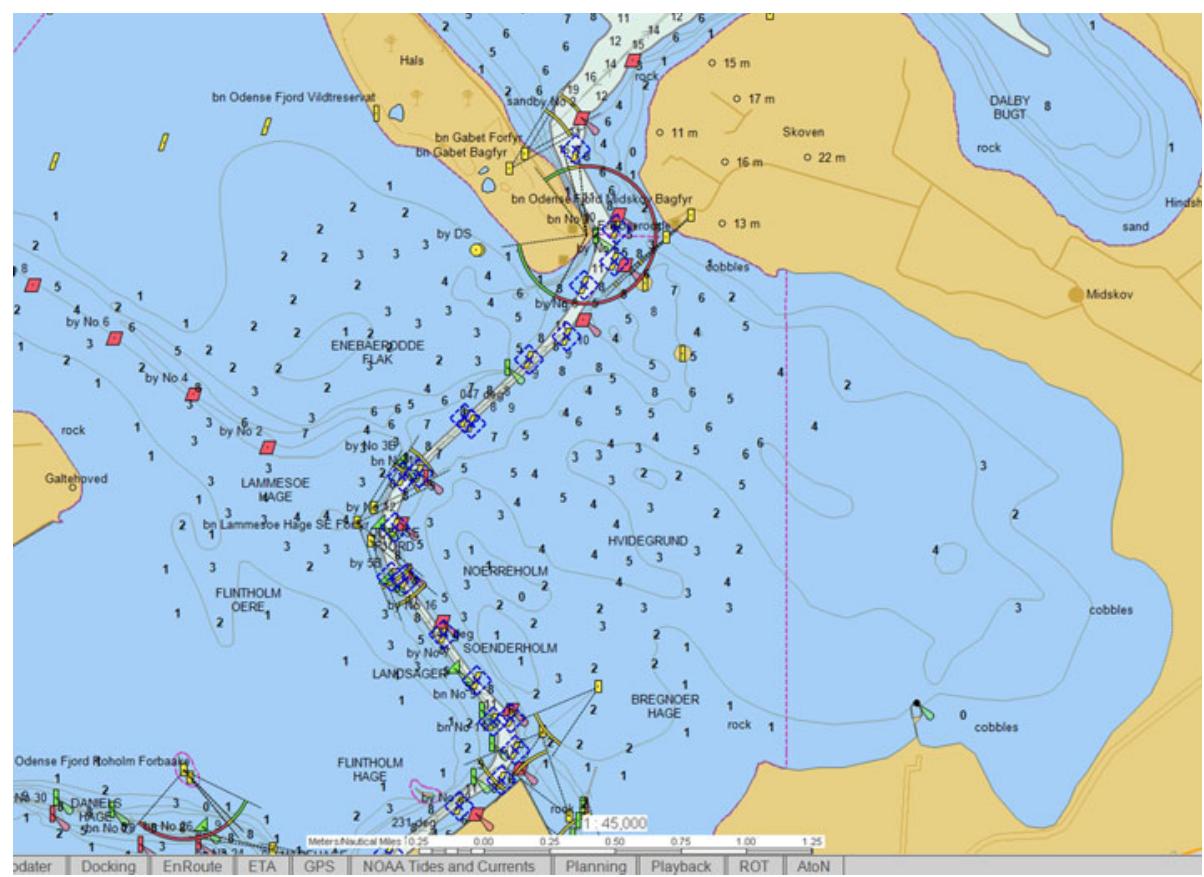

Figure 4. Odense Fjord area in Denmark with virtual AtoNs and S-AtoNs marking waterway borders. Source: EIVA.

AIS AtoNs objects but also for sending vessel- and application-specific messages. Ethernet and Wi-Fi interfaces increase operational flexibility as the device can be managed anywhere in the world. Naturally, robust encryption protocols and a built-in integrity monitoring feature assure privacy and safety of all networked data (Figure 4).

The application of AIS technology planned for the Nowy Świat-Elbląg waterway goes further, as it will also be used for broadcasting information about current dock queues and berthing points, and hydrometeorogical data.

\subsection{Hydrometeorological database}

Severe storms, strong winds, high waves and fog cause significant hazards to navigation. Different weather hazards can often occur simultaneously, or trigger cascading impacts from one extreme weather event. In order to support mariners operating along the Nowy Świat-Elbląg waterway, e-Navigation services will provide adequate hydrometeorological information delivered in a timely manner. The proposed hydrometeorological database, integrated with other e-Navigation services, serves exactly that purpose. The hydrometeorogical database integrates information from a variety of sensors including: 


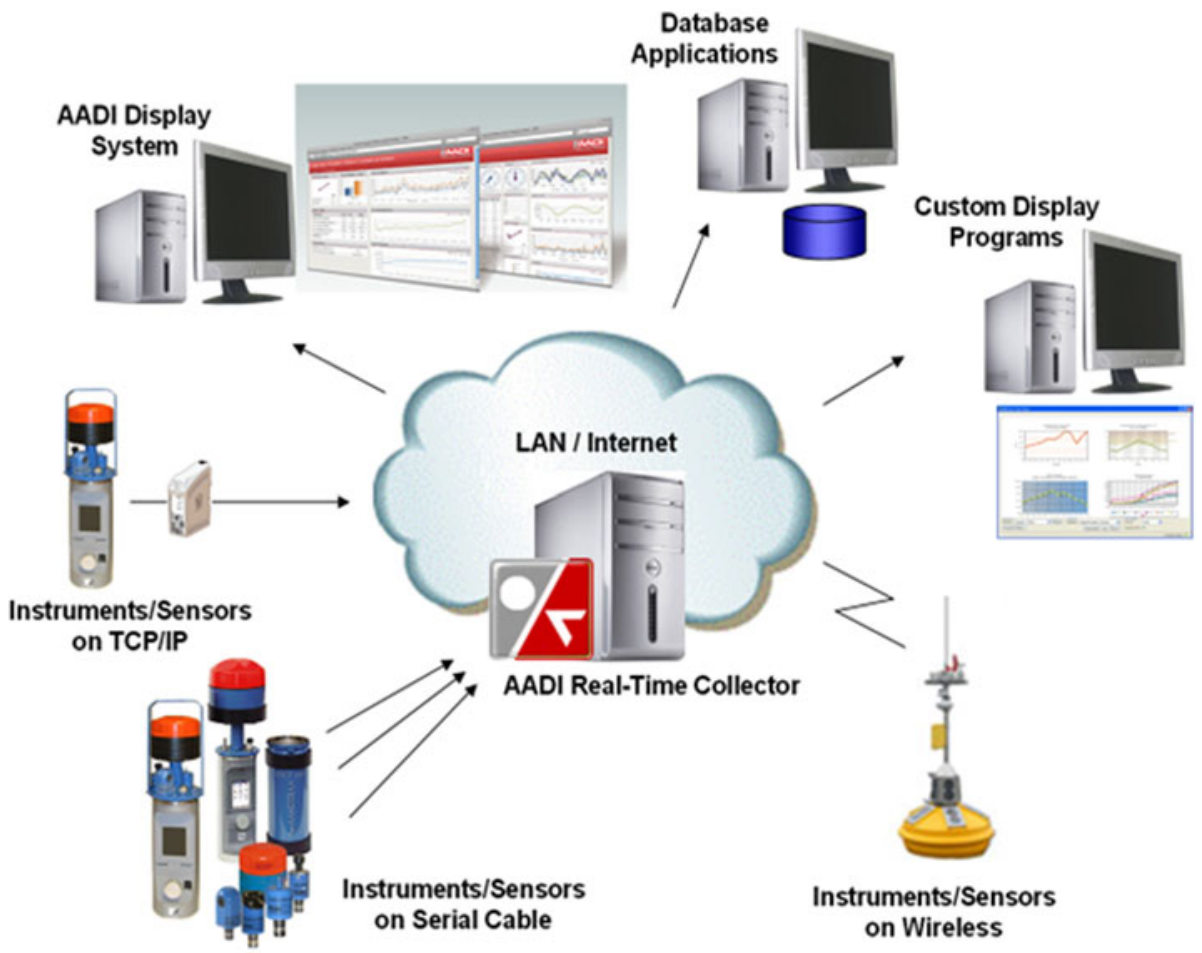

Figure 5. Hydrometeorological database integration system. Source: Tomaszewski et al. (2018).

anemometers, water level measuring sensors, wave measuring sensors and lighting detectors. All information from the hydrometeorological database will be integrated, transcoded into AIS messages and broadcast to mariners. Subsequently, hydrometeorological information will be displayed on the PPU screen used by maritime pilots. The hydrometeorological data will be available in real time both via AIS and Global System for Mobile communications link (Figure 5).

\subsection{Maritime asset monitoring and management system}

The advances of the e-Navigation concept can also be utilised to monitor and manage critical AtoNs within a specific area. To this end, the physical maritime infrastructure deployed along the waterway from Nowy Świat to Elbląg will be continuously monitored via a bidirectional multichannel communication system. In this system, every critical AtoN constitutes a 'smart station' capable of receiving instructions and sending back reports regarding its performance.

To achieve this objective, each monitored object will be equipped with two crucial elements: (1) a controller responsible for gathering, processing and storing all relevant information about its host (i.e., a buoy, beacon or landmark) and (2) a communication module to exchange information with the shore.

Confidentiality and integrity of transmitted data is assured at every level by the advanced encryption standard for group data encryption. Each 'smart station' working as part of the monitoring system will be capable of sending performance data and receiving commands according to a planned schedule (i.e., daily status updates) or on an ad-hoc/on-demand basis. Additionally, in case of any urgent or unexpected events (e.g., off position, unauthorised entry, collision with an object), a dedicated communication channel ensures that any triggered alert is delivered instantly to the operator (Figure 6).

The monitoring system architecture offers flexibility in the management and maintenance of remote assets. The compact form factor and low power consumption allows it to integrate seamlessly with any virtual station. The e-Navigation service provided by the control and monitoring system will vastly 


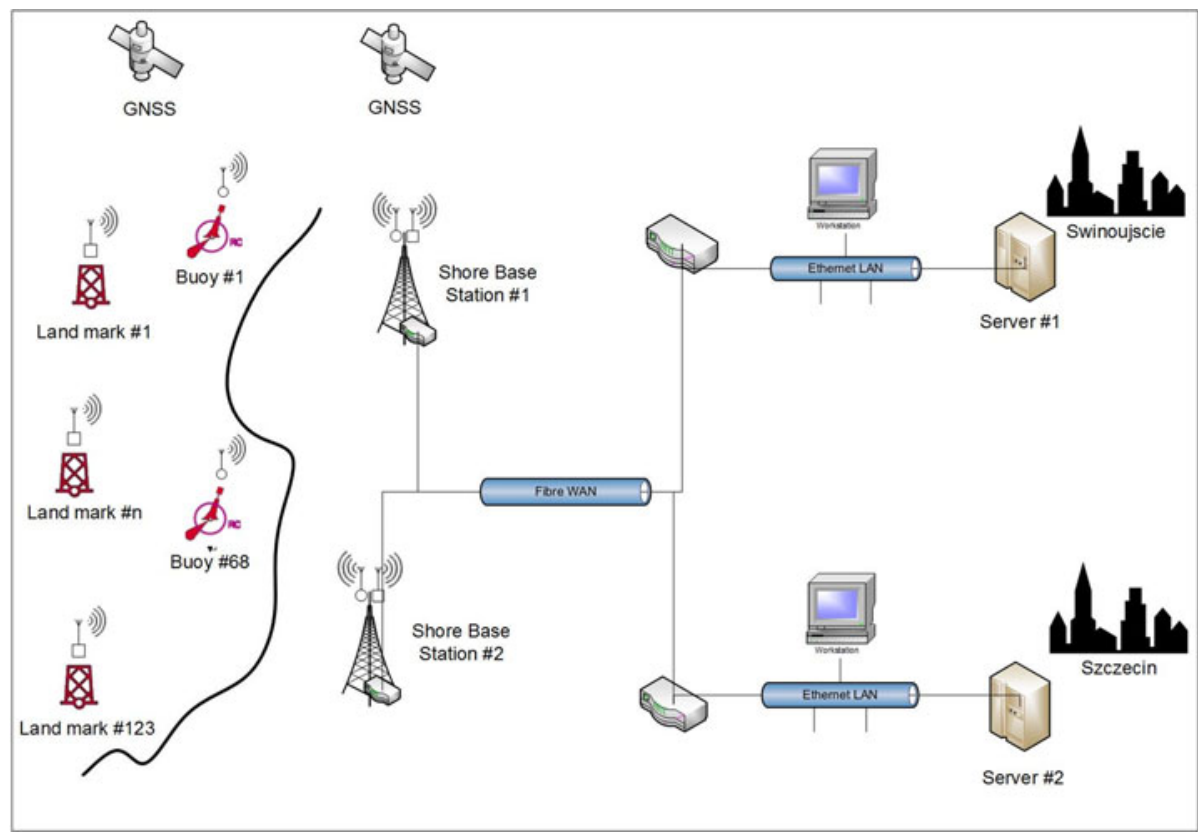

Figure 6. Diagram of the critical aids to navigation control and monitoring system.

improve domain and environmental awareness for mariners. If there is any inconsistency in an asset's performance or, even worse, a malfunction of any kind, the monitoring system should not only inform the system operator on the shore but also - with critical assets - appropriate notice should be transmitted directly to the pilot's PPU.

\subsection{Ground-based augmentation system}

It is hard to imagine today's marine navigation without GPS - or more broadly the global navigation satellite system (GNSS). Although not even three decades have passed since the launch of global satellite-based navigation, a GNSS receiver has become a fundamental device on every vessel. In most applications, stand-alone GNSS with an accuracy of around $10-20 \mathrm{~m}$ is sufficient for navigational purposes. However, to meet the IMO requirements for more safety-critical navigation, the stand-alone GNSS service is not sufficient. It is necessary to establish further infrastructure to improve accuracy. Potential options for this infrastructure include differential GNSS.

To increase the accuracy of the GNSS service specialised differential techniques can be applied. To this end the maritime world has adopted differential GPS (DGPS) and later - as the multi-carrier signal has become commonly available - differential GNSS (DGNSS). The idea behind DGNSS technology is to use a reference receiver with a surveyed position to generate and broadcast differential corrections to end-users. With the utilisation of DGNSS it is possible to reach even a sub-metre accuracy in determining a vessel's position.

Nevertheless, in some safety-critical applications (e.g., docking, precise navigation in constrained waters), even more accurate positioning is required. Real-time kinematic, or RTK, another differentialbased technology, is capable of delivering sub-decimetre accuracy. Although it has been utilised in hydrography for years, the usage for navigation purposes lagged somewhat behind. But increasing the accuracy of positioning, without assuring adequate integrity of measurements, is still questionable.

The Nowy Świat-Elbląg waterway, where providing reliable tools for safety-critical navigation is of the utmost importance, will benefit from a maritime ground-based augmentation system (GBAS) capable of providing RTK corrections and IALA-compliant integrity monitoring at the same time. To 
achieve this, each maritime GBAS is composed of a fully redundant reference station and monitoring station. The reference station generates RTK corrections in RTCM3.2 format and broadcasts its location (the typical range is up to $10-15 \mathrm{~km}$ ), whilst the monitoring station continuously monitors broadcast corrections to ensure data integrity. The hardware is managed by a dedicated and automated monitoring software which triggers alerts and executes intelligent algorithms to assure optimal performance.

Initial tests of the maritime GBAS technology were conducted in the Port of Rostock in 2006 (Schlüter et al., 2008). Although the hardware setup was very limited (only one temporary reference station) and without built-in integrity monitoring, the Rostock case study - as proof of the concept - showed the advantages and limitations of the GBAS technology. The maritime GBAS planned for the Nowy SwiatElbląg waterway will be a complete, fully operational system, compliant with the IALA requirements (IALA, 2008, 2011).

When navigating in constrained waters the terms 'precision', 'accuracy', 'confidence', 'reliability' and 'real-time' gain an entirely new meaning. The levels of uncertainty which are acceptable in open waters or more open waterways and harbours are often unacceptable in more constrained waters. As presented in the previous section, according to IMO regulations, required position accuracy should be no less than $0.1 \mathrm{~m}$ (or $10 \mathrm{~cm}$ ). Although this can seem very restrictive, in some cases it might not be enough to assure the safety of navigation (let alone efficiency). Naturally we are not claiming that there is much of a difference whether the position of a vessel (or more precisely its positioning antenna) is determined with an accuracy greater than $10 \mathrm{~cm}$. However, after considering that the error of position derivatives (e.g. along speed, bow/stern speed, rate of turn) is much bigger and that the navigation with small margins requires accurate manoeuvring parameters provided in near real-time, offering pilots tools supporting sub-centimetre accuracy, becomes of the utmost importance.

\section{Conclusions}

The proposed objective of the e-Navigation services for the Nowy Świat-Elbląg waterway is to enhance the safety of navigation and to reduce potential errors. The e-Navigation concept presented in this paper reaches beyond an 'adaptation period' proposed for e-Navigation and converts certain e-Navigation services and solutions into practice.

The analysis of the selected case study provides a better understanding of how the evolution and integration of land-based technology (e.g., GNSS-RTK GBAS, VAG) and ship-borne equipment (e.g., PPU, AIS receiver) can improve the domain and environmental awareness of the mariner. It also shows that $\mathrm{e}-$ Navigation solutions (e.g., virtual AtoNs) constitute a viable alternative to traditional navigational aids (e.g., buoys). Naturally, in most cases, traditional aids and e-Navigation solutions are complementary. However, as presented in this paper, e-Navigation services can also work as a 'stand-alone' solution, without traditional (physical) aids, especially in situations where using physical/traditional AtoN is for various reasons - not possible.

\section{References}

Digital Ship (2018). New e-Navigation and Compliance Platform from ChartCo. Digital Ship. Available at: https:// www.thedigitalship.com/news/electronics-navigation/item/5603-new-e-navigation-and-compliance-platform-from-chartco [Accessed 8 Aug. 2018].

EIVA. The Power of Virtual Buoys - How They Reduce Costs and Increase Safety. EIVA a/s, Skanderborg, Denmark. Available at: https://www.eiva.com/about/case-studies/navisuite-perio-lindoe-port-of-odense [Accessed 8 Aug. 2018].

Hagen, J. E. (2017). Implementing e-Navigation (Technology and Applications Series). Boston and London: Artech House.

IALA (2008). IALA Guideline No. 1062 on the Establishment of AIS as an Aid to Navigation. Edition 1. St Germain en Laye, France: International Association of Marine Aids to Navigation and Lighthouse Authorities.

IALA (2011). IALA Recommendation A-126 on the Use of the Automatic Identification System (AIS) in Marine Aids to Navigation Services. Edition 1.5. St Germain en Laye, France: International Association of Marine Aids to Navigation and Lighthouse Authorities.

IMO (2009). Report of the Maritime Safety Committee on its Eighty-Fifth Session. Strategy for the Development and Implementation of E-Navigation. MSC 85/26/Add.1, Annex 20. London: International Maritime Organization. 
IMO (2018). e-Navigation Strategy Implementation Plan - Update 1. MSC.1/Circ.1595. London: International Maritime Organization.

Maritime Logistics Professional (2018). Poseidon Navigation Services Inks Deal with Hapag-Lloyd. Maritime Logistics Professional. Available at: https://www.maritimeprofessional.com/news/poseidon-navigation-services-inks-deal-322557 [Accessed 15 Oct. 2018].

Misnik, B. (2014). Wpływ wykonania przekopu Mierzei Wiślanej na rozwój i funkcjonowanie portu Elblag. Logistyka, 6, 901-908.

Patraiko, D., Wake, P. and Weintrit, A. (2010). e-Navigation and the human element. The International Journal on Marine Navigation and Safety of Sea Transportation, 4(1), 11-16.

Pietraszkiewicz, J. and Tycholiz, W. (2018). Analiza działania Morskiej Stacji Referencyjnej w Świnoujściu jako podstawa do stworzenia morskich systemów IDS (Instrument Docking System). Zeszyty Naukowe Akademii Morskiej w Gdyni, Nr 107, s. 84-98 (Analysis of Operation of the Maritime Reference Station in Świnoujście as a Basis for Creating the Instrument Docking System (IDS)). Scientific Journal of Gdynia Maritime University, (107), 84-98.

Rødseth, Ø. J. (2016). Integrating IEC and ISO Information Models into the S-100 Common Maritime Data Structure. Copenhagen, Denmark: e-Navigation Underway International.

Schlüter, S., Engler, E., Noack, T., Beckheinrich, J., Hirrle, A., Becker, C., Klähn, D. (2008). GBAS-Technologies for High Precise Safety-Critical Maritime Navigation. Proceedings of the International Symposium Information on Ships (ISIS), September, Hamburg, Germany.

Tomaszewski, M., Tycholiz, W., Weintrit, A., Dobrzyński T. (2018). Koncepcja elektronicznego wspomagania nawigacji na drodze wodnej łączącej Zalew Wiślany z Zatoką Gdańską (The concept of electronic support of navigation on the waterway connecting the Vistula Lagoon with the Gulf of Gdańsk). Research project commissioned by the Maritime Office in Gdynia. Gdańsk: ProNaw Ltd.

Weintrit, A. (2011). Development of the IMO e-Navigation concept - common maritime data structure. In: Mikulski, J. (ed.). TST 2011, Communications in Computer and Information Science. vol. 239. Modern Transport Telematics. Berlin and Heidelberg: Springer, pp. 151-163.

Weintrit, A. (2013). Technical infrastructure to support seamless information exchange in e-Navigation. In: Mikulski, J. (ed.). TST 2013, Communications in Computer and Information Science. vol. 395. Activities of Transport Telematics. Berlin and Heidelberg: Springer, pp. 188-199.

Weintrit, A. (2016a). e-Nav, is it enough? International Journal on Marine Navigation and Safety of Sea Transportation, 10(4), 567-574.

Weintrit, A. (2016b). Relationships between e-Navigation, e-Maritime, e-Shipping and ITS. In: Mikulski, J. (ed.). TST 2016, Communications in Computer and Information Science. vol. 640. Challenge of Transport Telematics. Berlin and Heidelberg: Springer, pp. 487-498.

Weintrit, A., Wawruch, R., Specht, C., Gucma, L. and Pietrzykowski, Z. (2007). Polish approach to e-Navigation concept. International Journal on Marine Navigation and Safety of Sea Transportation, 1(3), 261-269.

Wingrove, M. (2019). Agreement creates low-cost e-Navigation service over L-band, Maritime Digitalisation and Communications. Available at: https://www.marinemec.com/news/view, agreement-creates-lowcost-enavigation-service-overlband_57164.htm.

Zwolan, P. and Czaplewski, K. (2015). Methodology of creation simulation basin based on the channel throught (sic) the Vistula spit. Annual of Navigation, 22(1), 5-20. doi:10.1515/aon-2015-0017.

Cite this article: Weintrit A, Pietraszkiewicz J, Piotrzkowski W, Tycholiz W (2021). e-Navigating in highly-constrained waters: a case study of the Vistula Lagoon. The Journal of Navigation 74: 3, 505-514. https://doi.org/10.1017/S0373463320000661 